\title{
Effect of the probiotic Lactobacillus reuteri on the immune status of piglets after weaning
}

\author{
A. Ovcharova, K. Ostrenko, E. Pyankova
}

All-Russian Research Institute of Physiology, Biochemistry and Animal Nutrition - Branch of the Federal Research Center for Animal Husbandry named after Academy Member L. K. Ernst, VNIIFBiP, Borovsk, 249013, Kaluga region, Russian Federation

*Corresponding author e-mail: ostrenkoks@gmail.com

Journal of Livestock Science (ISSN online 2277-6214) 13: 33-37

Received on 27/9/21; Accepted on 20/12/21; Published on 8/1/22

doi. 10.33259/JLivestSci.2022.33-37

\begin{abstract}
Weaning from piglets is a severe stress. First of all, the transition from dairy feeding to combined feeds negatively affects the digestive system and the immune system. Probiotics are used to reduce the negative impact of weaning stress. They allow you to target the intestinal microbiome and increase the immune status. The aim of the study was to study the effect of the compartment 2 strains of Lactobacillus reuteri on the indicators of nonspecific resistance and productivity of piglets. In the course of the conducted studies, an increase in the factors of nonspecific resistance of the body was found. In the experimental group, the phagocytic activity of neutrophils increased by $4.4 \%$, the phagocytic index was higher by $6.6 \%$ and the bactericidal activity increased by $29 \%$ compared to the control group. These indicators reflect the activation of the immune system, which is confirmed by an increase in lysozyme in the blood serum by $22 \%$. At the same time, there were no changes in the leukogram of the experimental and control groups. An increase in the immune status of piglets in the experimental groups affected the increase in body weight. For piglets treated with Lactobacillus reuteri, body weight was increased by $9.3 \%$, and the average daily gains in the control group increased by $15.8 \%$. The use of probiotics in the period of post-weaning stress allows you to activate the immune status.
\end{abstract}

Keywords: probiotic; Lactobacillus reuteri; nonspecific resistance; productivity; piglets. 


\section{Introduction}

In natural conditions, the transition from the mother's milk feeding to the basic diet (BD) occurs gradually over several weeks, during the same period, the active colonization of the newborn's body with various microorganisms and the formation of intestinal microflora takes place. Lactobacilli dominate in the microbiota of suckling pigs, while representatives of the genera Firmicutes and Bacteroides dominate in adult pigs (Yarmoc et al 2018, Konstantinov et al. 2006). In the modern practice of intensive pig breeding, piglets are weaned from sows at the age of 15 to 28 days. As a result of stress and a sharp change in the diet, the process of the intestinal microflora formation is disrupted. After weaning, the number of lactobacilli begins to decrease, opening the way for pathogenic microorganisms to colonize the intestines (Taranto et al 2003). In addition, the piglets weaning is a serious burden on the developing immune system, which adapts to changing feeding conditions against the background of stress. This leads to a decrease in energy and nutrient consumption, and increases the susceptibility of piglets to various infections (Buyarov et al 2014, Hou et al 2015). The postweaning period accounts for approximately 70-80\% of piglet deaths, $50 \%$ of which are losses due to gastrointestinal diseases, and in the animals that have been ill, there is a decrease in growth and development rates by $30-50 \%$ (Anikienko et al 2018). For the prevention and treatment of infectious diseases caused by postweaning stress, since the early 1950s, antibiotic drugs have been widely used. However, the irrational use of antibiotics leads to the appearance of drug resistance genes in opportunistic and pathogenic microorganisms, the accumulation of antibiotics in agricultural products, and the transfer of antibiotic resistance genes from animal strains of microorganisms to microbial strains of the human population (Chang et al 2001). In this connection, in 2006, the European Union introduced a ban on the use of feed antibiotics (Tedtova et al 2020). As an alternative to feed antibiotics and in order to normalize the intestinal microflora, preparations of living microorganisms - probiotics - have become widespread.

The action mechanism of probiotics on the macroorganism is diverse and multifaceted, but it is not yet well understood. One of the important functions of probiotic microorganisms is to protect the intestinal mucosa from pathogenic microflora by competing for nutrients, adhesion sites, and the synthesis of various bioactive substances. Intestinal lymphoid tissues, plasmocytes, and macrophages are the first to respond to intestinal antigens, such as food toxins, bacteria, and viruses. Thus, the intestinal mucosa is the first stage of the immune defense of the digestive system (Shin et al 2019). Probiotics have a positive effect on the condition of the intestinal mucosa. In piglets received probiotics, there is an increase in the height of the villi and the depth of the crypts (Moeser et al 2017). Macrophages play a key role in intestinal homeostasis maintaining by regulating cytokine secretion and an immune response generation (Cao et al 2020). Some types of probiotic lactobacilli can increase the activity of macrophages, the level of secretory immunoglobulin A, and lead to a decrease in the level of total cholesterol, lowdensity lipoproteins, and triglycerides (Bibikov, 2018). A number of authors suggest that probiotics can promote the formation of soluble factors that change the permeability of the villi, which affects the absorption of various substances in the small intestine (Anikienko et al 2018). One of the properties of probiotic strains is an increase in the enzymatic activity of the intestine. Carbohydrates are one of the most important components of the diet. In the digestive tract, carbohydrates are mainly digested by saliva and pancreatic amylases and decomposed into monosaccharides by sucrase, maltase, and lactase, then absorbed in the small intestine. According to a number of authors, the use of probiotic bacilli, lactobacilli and thermophilic streptococcus increases the activity of sucrase, maltase and lactase in the jejunum mucosa, and also leads to an increase in protease activity [Goyal \& Shukla, 2013).

The effectiveness of various probiotic preparations is different and depends on the types and strains of microorganisms that make up their composition, the dose of the preparation, the scheme of its use, the age and physiological state of the animals. At the same time, when developing new probiotic preparations, it is necessary to study in detail their effect on the physiological and biochemical status and productivity of the animals of the species for which they are intended, taking into account their physiological state, feeding conditions and maintenance (Chang et al 2001).

One of the most promising probiotic strains of Lactobacillus is Lactobacillus reuteri. It is dominant in the gastrointestinal tract of many mammals, one of the most well - studied lactobacilli, and is widely used as a probiotic in humans and animals. L. reuteri is a heterofermentative bacterium that is considered one of the few truly autochthonous species of Lactobacillus in humans and animals. Various gastrointestinal tract environmental conditions, such as influence of low $\mathrm{pH}$ in the stomach, contact with bile in the small intestine, etc., negatively affect on ingested probiotic microorganisms. The adhesion of the probiotic strain to enterocytes of the host intestinal mucosa is important for colonization, competition with pathogens, and interaction with the host intestinal immune cells (Mackenzie et al 2010). A number of authors have shown that L. reuteri has high adhesive properties to enterocytes. Possible adhesion mechanism for $L$. reuteri is the binding of bacteria to surface proteins, exopolysaccharide, glucosyltransferase A, and inulosaccharose. Lactobacilli modulate the activity of several genes encoding adhesive proteins, such as E-cadherin and $\beta$-catenin (Lebeer et al 2008). L. reuteri also synthesizes various antimicrobial substances, such as lactic acid, hydrogen peroxide, reuterin, and reutericycline (Gänzle et al 2000, Bian, 2008). In vitro studies have shown that L. reuteri strains inhibit the growth of many intestinal pathogens, including Escherichia coli, Salmonella Spp, Staphylococcus epidermidis, Staphylococcus aureus, Helicobacter pylori, and rotavirus (Ovcharova \& Petrakov 2018). In addition, L. reuteri can produce vitamin B12 (Morita et al 2008; Yarmoc \& Osepchuk 2008) and has the ability to synthesize L-lysine and folic acid (Hou et al 2015). 
The purpose of this study was to study the effect of L. reuteri probiotic on indicators of nonspecific resistance of piglets and productivity indicators.

\section{Materials and methods}

The strains Lactobacillus reuteri 395 and Lactobacillus reuteri 298 were used in the research. The strains were isolated from the intestines of healthy calves in the laboratory of microbial biotechnology All-Russian Research Institute of Physiology, Biochemistry and Animal Nutrition - Branch of the Federal Research Center for Animal Husbandry named after Academy Member L.K. Ernst (VNIIFBiP). A comparative analysis of the nucleotide sequences of 16S rRNA genes was carried out to identify the species belonging to Lactobacillus spp, and deposited in the VKM - All-Russian Collection of microorganisms (Sarukhanov et al 2007).

To obtain the preparation, L. reuteri strains 395 and 298 were individually grown on natural skimmed milk in a volume of 2.0 liters for 48 hours at $\mathrm{t} 38^{\circ} \mathrm{C}$, after which $5 \%$ sucrose and $5 \%$ skimmed milk powder were added to the grown culture as cryoprotectors, frozen in a low-temperature freezer and then subjected to lyophilic drying. After drying, the lyophilizate was crushed, homogenized, and the amount of CFU in $1 \mathrm{~g}$ was determined by seeding on a nutrient medium (MRS-agar) from a series of ten-fold dilutions, followed by visual counting of the grown colonies.

The research was conducted on the vivarium of VNIIFBiP $(55.211079191954155,36.45705751971536)$ on crossbred piglets ( $\delta$ Danish Yorkshire $\times q$ Danish Landrace) at 45 days of age immediately after weaning. According to the principle of analogous pairs, taking into account the live weight, two groups of piglets with 10 heads each were formed. Group maintenance was carried out in cages, drinking was from auto drinkers.

The animals of the control group received a complete SCC-51 (BD). Piglets of the second (experimental) group, in addition to the BD, received $1 \mathrm{~g}$ / head of a mixture of $L$. reuteri strains 395 and 298 daily for 30 days. The amount of CFU in $1 \mathrm{~g}$ was $10^{10}$. To obtain a feed additive, the lyophilizates were mixed in a ratio of 1:1, stored at 4 ${ }^{\circ} \mathrm{C}$. The duration of the experiment was 1 month, during which the general condition of the animals was monitored daily. During the experiment, the feed consumption and its consumption per unit of growth were taken into account. The piglets were weighed at the beginning and end of the experiment. The study of the microflora of the digestive tract was carried out by microbiological investigations of feces, which were obtained by the act of forced defecation.

At the end of the experiment, blood was taken from the mammary vein in animals from each group to study hematological and biochemical parameters. The number of red blood cells and white blood cells, the level of hemoglobin was determined by an automatic hematological analyzer Mindray BC-2800 Vet. The calculation of the leukocyte formula was carried out in smears stained according to Romanovsky-Giemsa (Kondrakhin et al 2004). The phagocytic number and phagocytic index were determined using a direct morphological method (Chasovskih et al, 2019), with the E. coli strain 113-3 used as a test culture. The bactericidal activity of blood serum was determined according to the method of Hirsch (Hirsch J.G.) The bactericidal activity of blood serum was determined according to the modified method of Sarukhanov (Sein \& Chernikov 2018). The content of lysozyme was determined by the method of Emelianenko (1980). The t-test was used to assess the reliability of the average intergroup differences.

\section{Results and discussion}

Throughout the entire experiment, the animals were healthy and ate feed well. The growth efficiency indicators of piglets when they were kept on diets with the addition of L. reuteri were higher than in the animals of the control group (Table 1).

At the beginning of the experiment, the live weight of the experimental piglets was $13.30 \pm 0.37 \mathrm{~kg}$. At the end of the experiment, the average live weight of piglets who received L. reuteri was $33.80 \pm 0.8 \mathrm{~kg}$, and of the control group piglets $-31.0+0.81 \mathrm{~kg}$, which is $9.03 \%$ higher. The average daily gains were significantly $(\mathrm{P}<0.05)$ higher in piglets who received L. reuteri and amounted to $586 \pm 28 \mathrm{~g}$, while in the control group it was $506 \pm 16 \mathrm{~g}$, which is $15.8 \%$ higher compared to the control group. The viability in all groups was one hundred percent.

At the same time, feed costs per $1 \mathrm{~kg}$ of gain in piglets who received L. reuteri were $13.6 \%$ lower compared to the control group, even taking into account the cost of a probiotic supplement. This is consistent with the data of Yarmots et al 2018, who used the probiotic "Enterol" in young pigs during rearing and fattening and received an increase in profitability by $4.07 \%$ compared to the control group (Yarmoc \& Osepchuk 2008). The use reduced the cost of crude protein by $1 \mathrm{~kg}$ of gain in piglets who received L. reuteri by 13.4 and exchange energy by 13.6 compared to the animals of the control group.

In the assessment of nonspecific resistance of the organism, there is certain significance in hematological profile, changes in which are an important indicator of the external environment influence on the body (Molyanova 2010). Hematological parameters in all piglets were within the physiological norm; however, there was a tendency to increase the content of hemoglobin and red blood cells in piglets in the group receiving the L. reuteri supplement. Sein et al 2018, using the probiotic "Mucinol" in weaned piglets, received a significant increase in the blood of experienced piglets in the content of red blood cells and an increase in average daily body weight gains (Seo et al 2010) (Table 2). 
Table 1. Live weight, average daily gains, consumption of feed, crude protein and metabolic energy in piglets

\begin{tabular}{|l|l|l|}
\hline \multicolumn{1}{|c|}{$(\mathrm{n}=10)$. } \\
\hline Live wt. at the beginning of the experiment, $\mathrm{kg}$ & $13.30+0.37$ & $13.30 \pm 0.51$ \\
\hline Live wt. at the end of the experiment, $\mathrm{kg}$ & $31.00+0.81$ & $33.8 \pm 0.80$ \\
\hline$\%$ to the control & & 109.03 \\
\hline Live wt. gain, kg & $17.70 \pm 0.58$ & $20.50 \pm 0.96$ \\
\hline Average daily gain, $\mathrm{g}$ & $506 \pm 16$ & $586 \pm 28^{*}$ \\
\hline \multicolumn{1}{|c}{$\%$ to the control } & & 115.8 \\
\hline Feed consumed per period, $\mathrm{kg}$ & $48 \pm 2$ & $48 \pm 1.8$ \\
\hline
\end{tabular}

Table 2. Hematological parameters of piglets $(n=10)$

\begin{tabular}{|l|l|l|}
\hline & \multicolumn{1}{|c|}{ Control } & L. reuteri \\
\hline Hemoglobin, g / 1 & $130.89 \pm 0.15$ & $139.99 \pm 1.23$ \\
\hline White blood cell count, $10^{9} / 1$ & $11.05 \pm 0.13$ & $10.45 \pm 0.17$ \\
\hline Red blood cell count, $10^{12} / 1$ & $6.24 \pm 0.47$ & $7.01 \pm 0.20$ \\
\hline Leucogram, \% & & \\
\hline Basophils, \% & 1.6 & 1.6 \\
\hline Eosinophils, \% & 4 & 2.5 \\
\hline Neutrophils: & & \\
\hline Band forms, \% & 0.6 & 0.7 \\
\hline Segmented, \% & 35.1 & 35.6 \\
\hline Lymphocytes, \% Note:*- $<<0.05$, compared to the control group \\
\hline Monocytes, \% & 55.6 & 57.5 \\
\hline \multicolumn{2}{|l}{} \\
\hline
\end{tabular}

Table 3. Indicators of nonspecific resistance of piglets $(n=10)$

\begin{tabular}{|l|l|l|}
\hline \multicolumn{1}{|c|}{ Indicator } & Control & L. reuteri \\
\hline Phagocytic activity, \% & $45.2 \pm 1.15$ & $47.2 \pm 2.2$ \\
\hline Phagocytic index & $5.40 \pm 0.13$ & $5.76 \pm 0.14$ \\
\hline Blood serum bactericidal activity, \% & $56.7 \pm 3.2$ & $73.4 \pm 4.2^{*}$ \\
\hline The content of lysozyme in the blood serum, mcg/mcl & $58.0 \pm 2.4$ & $71.2 \pm 1.41$ \\
\hline \multicolumn{2}{|r|}{ Note:*- $<<0.05$, compared to the control group }
\end{tabular}

One of the most important properties of probiotic preparations is their ability to increase the immune status of the organism. It has been shown that the use of probiotics in industrial pig breeding activates the absorption and digesting ability of phagocytes, an increase in the level of lysozyme and secretory immunoglobulins (Buyarov et al 2014). In our research, when studying the effect of the introduced cultures on the overall immune status of animals, phagocytic and bactericidal activity, as well as the content of lysozyme in the blood serum, were determined. Indicators of nonspecific resistance of piglet blood serum are shown in Table 3.

As shown in the table, in the blood serum of animals of the experimental groups, the content of lysozyme and the total bactericidal activity significantly increased, while the phagocytosis indicators in all groups were approximately at the same level. As is known, the main phagocytic blood cells are neutrophils. The content of neutrophils in the blood of all the observed animals during the experiment did not significantly differ, the introduced probiotic supplement did not have a significant effect on their activity.

Conclusion In the course of the conducted researches, it was found that the introduction of a probiotic strain of $L$. reuteri into the basic diet of weaned piglets has a stimulating effect on the digestive system. It is expressed in the growth rate of piglets, and the weight gains at the end were higher by $9.3 \%$ compared to the control group. When recalculating to the average daily weight gain, in the experimental group it was $15.8 \%$ higher than in the control group. At the same time, feed costs per $1 \mathrm{~kg}$ of growth decreased by $13.6 \%$. Probiotic microorganisms have a stimulating effect on the immune system of the intestinal mucosa and on the nonspecific immune defense of the organism at large. In our research, the addition of $L$. reuteri to the diet of weaned piglets led to positive changes in the microflora of the digestive tract, which affected the increase in the bactericidal activity of blood serum and the content of lysozyme in serum. Thus, the use of probiotics in the postweaning period helps to increase the nonspecific resistance and productivity of piglets.

\section{References}

1) Anikienko I.V., Ilyina O.P., Karelina L.N., Silkin I.I. 2018. Mechanisms of action of probiotic drugs on the body, prospects for use in pig breeding. Bulletin of the IrGSHA. 2018. No. 84. pp. 126-135.

2) Bibikov S. 2018. Microbial ecosystem and immunity of the intestinal mucosa of pigs. Efficient animal husbandry. 2 (141): 16-17.

3) Bian L. 2008. An in vitro antimicrobial and safety study of Lactobacillus reuteri DPC16 for validation of probiotic concept. Master thesis: Massey University; 2008. 
4) Buyarov V.S., CHervonova I.V., YArovan N.I., Uchasov D.S., Sein O.B., Probiotiki I. 2014, Prebiotiki v promyshlennom svinovodstve i pticevodstve ,Orel.

5) Cao X, Tang L, Zeng Z, Wang B, Zhou Y, Wang Q, Zou P, Li W. 2020. Effects of Probiotics BaSC06 on Intestinal Digestion and Absorption, Antioxidant Capacity, Microbiota Composition, and Macrophage Polarization in Pigs for Fattening. Frontiers in Veterinary Science 7:570593.

6) Chang Y.H., Kim J.K., Kim H.J., Kim W.Y., Kim Y.B., Park Y.H. 2001. Selection of a potential probiotic Lactobacillus strain and subsequent in vivo studies. Antonie Van Leeuwenhoek 80: 193-9.

7) Chasovskih O.V., Pilip L.V., Byakova O.V 2019. Immunologiya Uchebno-metodicheskoe posobie Pod redakciej I.V. Okisheva, Kirov s. 40-43 URL: https://www.elibrary.ru/item.asp/id=42350855

8) Emel'yanenko P.A 1980. Metodicheskie ukazaniya po testirovaniyu estestvennoj rezistentnosti telyat. - M., s. 37

9) Gänzle MG, Höltzel A, Walter J, Jung G, Hammes WP. 2000. Characterization of reutericyclin produced byLactobacillus reuteri LTH2584. Applied and Environmental Microbiology 66:4325-33.

10) Goyal N, Shukla G. 2013. Probiotic Lactobacillus rhamnosus GG modulates the mucosal immune response in giardia intestinalis-infected BALB/c mice. Digestive Diseases and Sciences 58:1218-25. doi: 10.1007/s10620012-2503-y

11) Hou C, Zeng X, Yang F, Liu H, Qiao S. 2015. Study and use of the probiotic Lactobacillus reuteri in pigs: a review. Journal of Animal Science and Biotechnology. 6(1):14. doi: 10.1186/s40104-015-0014-3

12) Kondrakhin I.P., Arkhipov. A.V., Levchenko V.I. 2004. Methods of veterinary clinical laboratory diagnostics / M.: KolosS. - 2004. - 520 p.

13) Konstantinov S.R., Awati A.A., Williams B.A., Miller B.G., Jones P., Stokes C.R., 2006. Post-natal development of the porcine microbiota composition and activities. Environmental Microbiology 8(7): 1191-9. doi: 10.1111/j.1462-2920.2006.01009.x

14) Lebeer S., Vanderleyden J., De Keersmaecker S.C. 2008. Genes and molecules of lactobacilli supporting probiotic action. Microbiology and Molecular Biology Reviews. 72:728-64. doi: 10.1128/MMBR.00017-08.

15) Mackenzie D.A., Jeffers F., Parker M.L., Vibert-Vallet A., Bongaerts R.J., Roos S., 2010. Strain-specific diversity of mucus-binding proteins in the adhesion and aggregation properties of Lactobacillus reuteri. Microbiology.; 156:3368-78. doi: 10.1099/mic.0.043265-0.

16) Moeser A.J., Pohl C.S., Rajput M. 2017. Weaning stress and gastrointestinal barrier development: Implications for lifelong gut health in pigs. Animal Nutrition 3: 313-321.

17) Molyanova G.V. 2010. The influence of changing microclimate conditions on the cellular composition of the blood of pigs of different genotypes. Izvestiya Orenburg State Agrarian UniversityOrenburg 28(1): 284-287.

18) Morita H., Toh H., Fukuda S., Horikawa H., Oshima K., Suzuki T., 2008. Comparative genome analysis of Lactobacillus reuteri and Lactobacillus fermentum reveal a genomic island for reuterin and cobalamin production. DNA Research 15:151-61. doi: 10.1093/dnares/dsn009.

19) Mukai T., Asasaka T., Sato E., Mori K., Matsumoto M., Ohori H.. 2002. Inhibition of binding of Helicobacter pylori to the glycolipid receptors by probiotic Lactobacillus reuteri FEMS Immunology and Medical Microbiology 32:105-10. doi: 10.1111/j.1574-695X.2002.tb00541.x.

20) Ovcharova A.N., Petrakov E.S. 2018. New probiotic preparations based on Lactobacillus reuteri and prospects for their use in animal husbandry Problems of biology of productive animals. 2: 5-18. DOI: 10.25687/19966733.prodanimbiol. 2: 5-18

21) Sarukhanov V.Ya., Isamov H.H., Mirzoev E.B., Kobyalko V.O. 2007. Modification of the method for determining the bactericidal activity of the blood of farm animals. Agricultural Biology, 2: 119-122

22) Sein O.B., Chernikov D.P. 2018. The effect of the probiotic drug "Mucinol" on the physiological and biochemical status of pigs. Bulletin of the Kursk State Agricultural Academy 4: 115-118.

23) Seo B.J., Mun M.R., Rejish Kumar J., Kim C.J., Lee I., Chang Y.H., 2010. Bile tolerant Lactobacillus reuteri isolated from pig feces inhibits enteric bacterial pathogens and porcine rotavirus. Veterinary Research Communications 34:323-33. doi: 10.1007/s11259-010-9357-6.

24) Shamilova T.A., Shamilov N.M.2013. Vliyanie probiotika na mikrofloru i gistomorfologiyu kishechnika porosyat pri smeshannom mikotoksikoze . Uchenye zapiski Kazanskoj gosudarstvennoj akademii veterinarnoj mediciny im. N.E. Baumana. T. 215. S. 355-359.

25) Shin D., Chang S.Y., Bogere P., Won K., Choi J.Y., Choi Y.J., Lee H.K., Hur J., Park B.Y., Kim Y., Heo J. 2019. Beneficial roles of probiotics on the modulation of gut microbiota and immune response in pigs. PLoS One. 28: 14(8):e0220843. doi: 10.1371/journal.pone.0220843.

26) Tedtova V.V., Temiraev R.B., Kairov V.R., Dzhaboeva A.S., Yurina N.A., Temiraev K.B., Baeva Z.T., Bobyleva L.A., Zagaraeva E.F., Efendiev B.S. 2020. Effect of soybean feeding on productivity of sows, growth of piglets and quality of pork. Journal of Livestock Science 11:20-25. doi. 10.33259/JLivestSci.2020.20-25.

27) Taranto MP, Vera JL, Hugenholtz J, De Valdez GF, Sesma F. 2003. Lactobacillus reuteri CRL1098 produces cobalamin. Journal of Bacteriology 185:5643-7. doi: 10.1128/JB.185.18.5643-5647.2003

28) Yarmoc A.V., Osepchuk D.V. 2018. Primenenie probiotika "Enterol" pri otkorme svinej. Sbornik nauchnyh trudov Krasnodarskogo nauchnogo centra po zootekhnii i veterinarii. T. 7. № 2. S. 253-256 